\title{
The Role of Trichoscopy in Keratosis Follicularis Spinulosa Decalvans: Case Report and Review of the Literature
}

\author{
Aurora Alessandrini ${ }^{a}$ Giancarlo Brattoli ${ }^{b}$ Bianca Maria Piraccinia \\ Ambra Di Altobrando $^{a}$ Michela Starace $^{a}$ \\ aDermatology, Department of Experimental, Diagnostic and Specialty Medicine (DIMES), University of Bologna, \\ Bologna, Italy; bermatology Unit, Department of Medicine (DIMED), University of Padova, Padova, Italy
}

\section{Established Facts}

- Keratosis follicularis spinulosa decalvans is a rare, X-linked, hereditary disorder of keratinization, characterized by skin involvement and progressive scarring alopecia.

- Pathology is mandatory for the diagnosis.

- Trichoscopy is a noninvasive technique routinely used in the evaluation of hair diseases.

\section{Novel Insights}

- Trichoscopy is a very important tool that can suggest this rare diagnosis.

- Thanks to trichoscopy, it is possible to select the most appropriate site for scalp biopsy and also follow the results of treatments.

\section{Keywords}

Keratosis follicularis spinulosa decalvans · Scarring alopecia · Trichoscopy · Pathology

\section{Abstract}

Introduction: Keratosis follicularis spinulosa decalvans (KFSD) is a rare, X-linked, hereditary disorder of keratinization, characterized by skin involvement and progressive scarring alopecia of scalp, eyebrows, and eyelashes. The diagnosis is helped by the particular clinical features, but pathology is mandatory. Case Presentation: We described a case of a female patient referred to the outpatient's hair consultation of our department, in which we performed trichos- copy as a very useful tool for the diagnosis, followed by pathology that confirmed KFSD. Conclusion: In our article, we underlined the importance of trichoscopy for the diagnosis of this hair disease, with also a review of the literature on diagnosis and treatment.

(c) 2020 S. Karger AG, Basel

\section{Introduction}

Keratosis follicularis spinulosa decalvans (KFSD) is a rare, X-linked, hereditary disorder of keratinization, characterized by diffuse follicular hyperkeratosis, progressive scarring alopecia of scalp, eyebrows, and eyelash-

Aurora Alessandrin

Division of Dermatology, Department of Experimental, Diagnostic and Specialty Medicine University of Bologna, Via Massarenti 1

IT-40138 Bologna (Italy)

aurora.alessandrini.30@gmail.com 

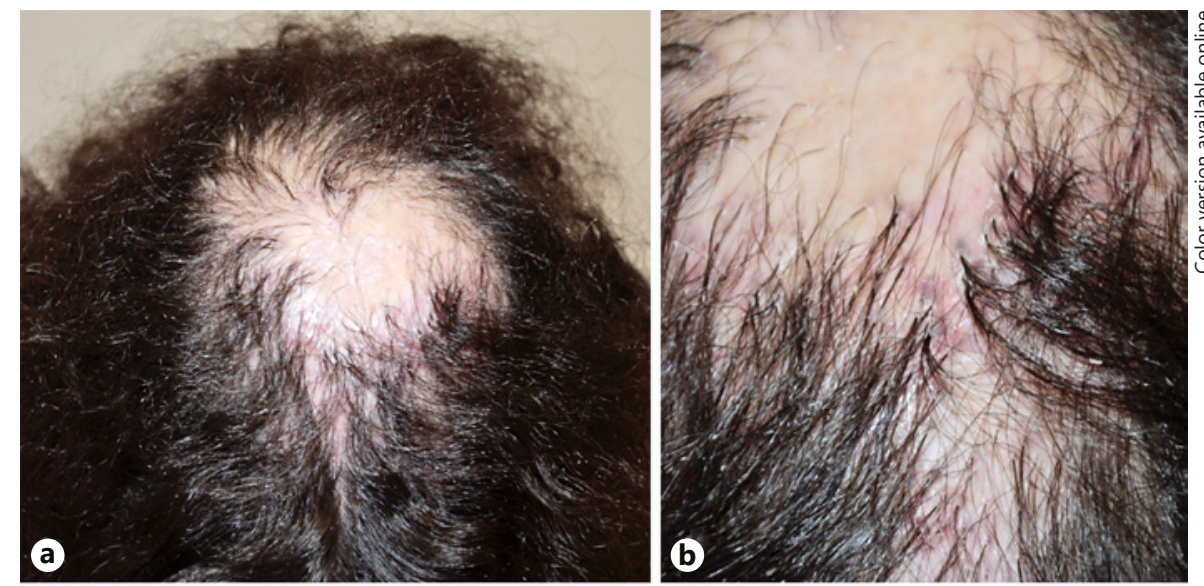

Fig. 1. Clinical pictures of our case with scalp (a, b) and face (c, d) involvement.
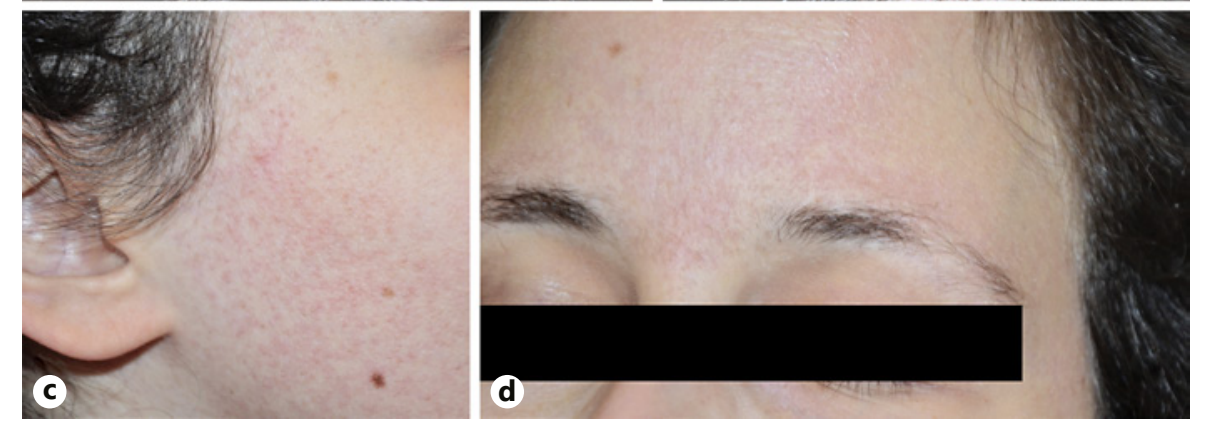

es and may be accompanied by photophobia, corneal and conjunctival inflammation and dystrophy, tooth abnormalities, ichthyosiform xerosis, facial erythema, atopic dermatitis, other hair disorders, and nail dystrophies [1]. The gene has been mapped to Xp21.2-p22.2 [2]. This condition mainly affects males with females being carriers and will have milder symptoms. Usually, KFSD begins during infancy with the appearance of follicular keratotic papules on the face, trunk, and limbs. The scalp is involved later with follicular erythematous papule, non-purulent inflammation, and scarring alopecia. Even if the examination of all body is crucial for the suspect diagnosis, scalp biopsy is mandatory for the rarity of the hair disease, showing distinguishing features as peri- and intrafollicular spongiosis and neutrophilic pustule formation in acute lesions [3]. There is no specific treatment for this disorder. However, drugs such as isotretinoin and dapsone have been tried; emollients, topical corticosteroids, and keratolytic agents can be also used. Genetic counseling is needed in all cases [4]. As mentioned, clinical examination is crucial for the diagnostic suspicion and pathology is mandatory. Therefore, in our experience, trichoscopy is fundamental for the diagnosis of hair diseases, and in this manuscript, we underlined the impor- tance of this technique also in KFSD. We described a case of KFSD in a female patient, proved by pathology, in which trichoscopy played an important role helping the differential diagnosis versus non-cicatricial alopecia, showing the typical signs of a cicatricial alopecia and selecting the best place to perform scalp biopsy.

\section{Case Report}

A 26-year-old Caucasian female was referred to outpatient's hair consultation of the Department of Specialist, Diagnostic and Experimental, Dermatology uint, for a history of alopecic patches of the scalp, gradually increased in size in the past few months. The patient referred severe itching and hair shedding on the scalp and also on the eyebrows and eyelashes. No history of familial hair or skin disorders was present. At the time of examination, the clinical manifestation of the scalp showed the presence of a large scarring patch of alopecia, with erythema and scales at the periphery. Tufted folliculitis was evident even with the naked eye. Examination of the whole skin of the patient revealed the presence of keratosis pilaris and small papules, especially on the face (Fig. 1). Trichoscopy of the alopecic patches, performed using FotoFinder dermatoscope (Teachscreen Software, Bad Birnbach, Germany) showed loss of follicular ostia, more visible in the center of the patch but also in the surrounding areas, and perifollicular hyperkeratosis. At the periphery of the affected area, we observed tufted hair, visible as many 

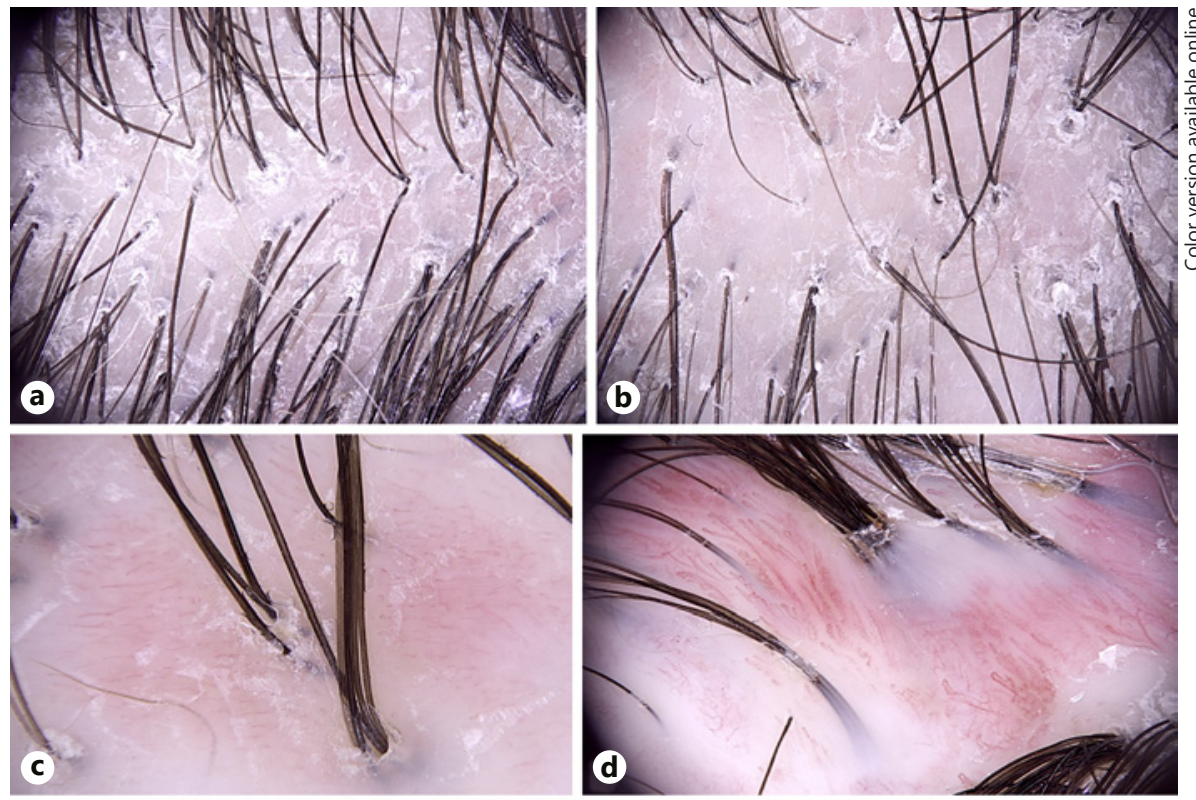

Fig. 2. Trichoscopy of KFSD showed diffuse perifollicular hyperkeratosis (a) with absence of follicular ostia (b). Magnification at $\times 70$ of tufted folliculitis (c, d) with visualization of elongated vessels (d). Trichoscopy of eyebrows (e) and eyelashes (f) showed yellow dots and dystrophic hair. KFSD, Keratosis follicularis spinulosa decalvans.
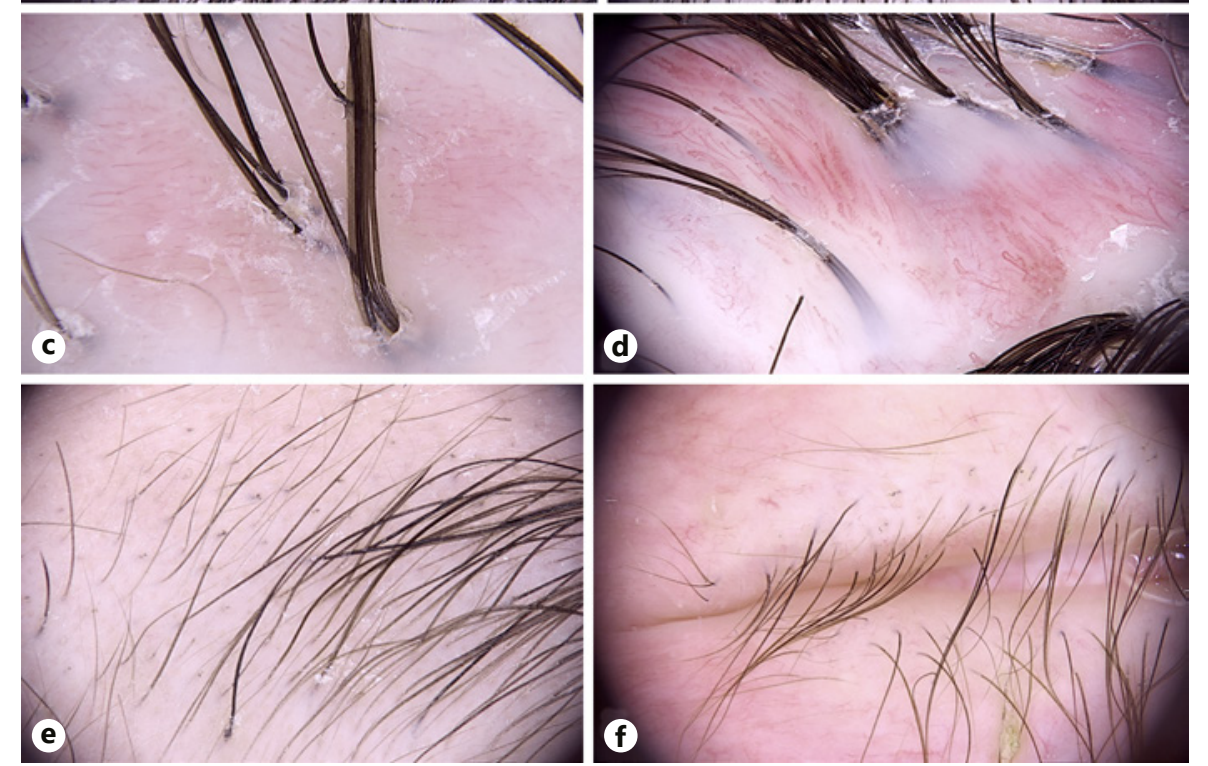

hairs coming out of a single follicle, and hairpin-elongated capillaries and linear serpentine vessels, sometimes parallel to emergence of hair shafts. At eyebrows and eyelashes, yellow dots and dystrophic hair were present (Fig. 2). These findings, both in the scalp and at eyebrows and eyelashes, suggested us the diagnosis. A 5-mm punch biopsy, guided by trichoscopy, was performed, from the margin of an alopecic area of the scalp and confirmed the suspected diagnosis of KFSD (Fig. 3). We performed genomic analysis to localize the KFSD gene. Our data confirmed X linkage of KFSD in this patient and tentatively map the gene on Xp22.2 p21.2. The patient was treated with keratolytic cream on the face and systemic isotretinoin $(0.3 \mathrm{mg} / \mathrm{kg} / \mathrm{day})$ for 6 months with a complete resolution of the clinical signs on the face and a great improvement of the scalp signs. Due to the severe area of hair loss, after 3 months, we added minoxidil 5\% solution twice a day with an increased hair density and better covering of the affected area. No side effects were reported by the patient, who was completely satisfied of the results.

\section{Discussion}

KFSD is an exceedingly rare variant of keratosis pilaris atrophicans characterized by follicular keratosis and progressive cicatricial alopecia involving the scalp, eyebrows, and eyelashes. KFSD has been also classified under the lymphocytic group of primary cicatricial alopecia [5]. This condition, along with keratosis atrophicans faciei and atrophoderma vermiculatum, represents closely related disorders (Table 1). Recently, a fourth type, named folliculitis spinulosa decalvans, has been proposed previously considered to be a persistent inflammatory variation of keratosis follicularis decalvans [6]. KFSD is an uncommon X-linked dominant disorder, and it was first mentioned by Siemens [7]. The gene has been mapped to Xp22.13-p22.2 in subsequent studies [8]. However, an autosomal dominant and sporadic inheritance has also been reported $[9,10]$. Another appellation, folliculitis spinulosa decalvans, defines the autosomal dominant form, which could be differentiated from the commoner Xlinked one by more pronounced follicular inflammation, particularly evident on the scalp [11]. Usually, men are more severely affected, whereas female heterozygotes may exhibit a milder phenotype in families with an Xlinked dominant inheritance [12]. The process of lyonization (non-random $\mathrm{X}$ inactivation) may explain expres- 

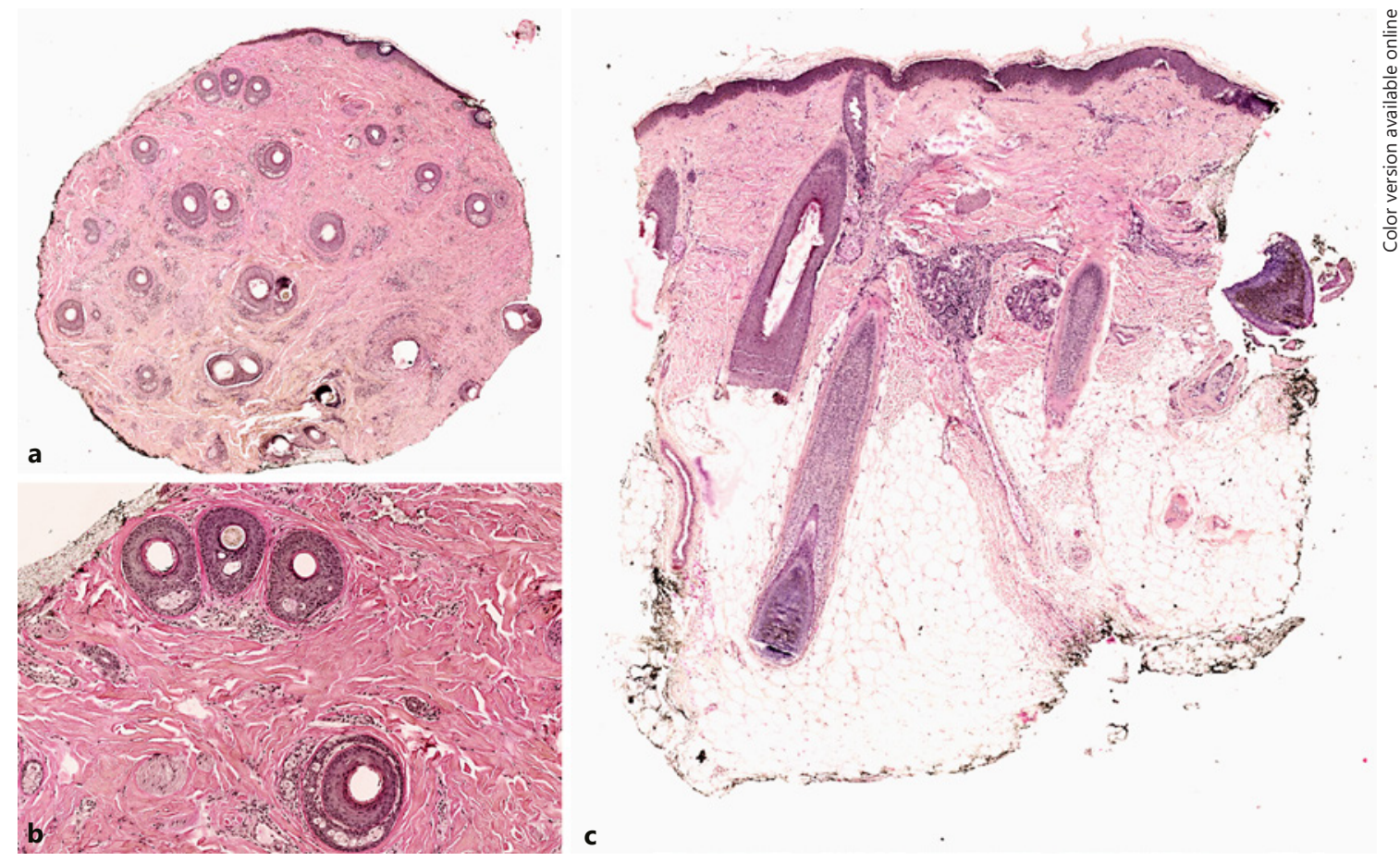

Fig. 3. Pathology sections: a Horizontal section: decreased number of sebaceous glands and hair follicular units. Diffuse fibrosis. H\&E, $\times 2$. b Horizontal section: fibrosis, sebaceous structures in the follicular unit. $H \& E, \times 10$. c Vertical section: severe and diffuse fibrosis, rare sebaceous glands, and decreased number of the follicles. H\&E, $\times 2$.

sion of KSFD in women $[13,14]$. KFSD patients carry mutations in the MBTPS2 (membrane-bound transcription factor peptidase site 2) gene, which required for cleavage of sterol regulatory element-binding protein. Therefore, its alteration leads to disturbed epidermal differentiation due to inhibition of cholesterol biosynthesis [15]. The adverse impact on epidermal lipid composition results in disturbed barrier function. This leads to increased transepidermal water loss, disturbed cytokine production, epidermal hyperplasia, hyperkeratosis, and inflammation, akin to many inherited ichthyoses [16].

Clinically, keratosis pilaris and facial erythema usually begin on the face in infancy and may progress on the trunk and limbs. Scarring alopecia of the scalp subsequently occurs in childhood or early adolescence and slowly progresses with follicular inflammation and fibrosis [17]. Alopecia may be patchy or widespread. The main clinical characteristics of the disease are diffuse cutaneous follicular hyperkeratosis and progressive scarring alopecia of the scalp, eyebrows, and eyelashes. Rare associated features include palmoplantar keratoderma, with predilection for the calcaneal region, and the unusual sign of high cuticles (or long cuticles) [18]. Ocular abnormalities such as photophobia, blepharitis, keratitis, corneal dystrophy, conjunctivitis, congenital glaucoma, and lenticular cataract have been described in several patients with KFSD [17]. Less commonly reported features are atopy, hyperkeratosis of the palms and soles, deafness, mental retardation, aminoaciduria, and tufted hair folliculitis or woolly hair among hair abnormalities [18-20]. Nail alterations such as cuticular hypertrophy and leukonychia may also be present [21]. Furthermore, KFSD has been described in association with various conditions, including cutis laxa, "big pinnae," clinodactyly, arachnodactyly, Noonan's syndrome, Down's syndrome, hepatomegaly, and bilateral inguinal hernia [17, 22, 23]; a greater propensity to recurrent systemic bacterial infections has also been reported [18]. Severe pruritus could be present, and it could be related to increased levels of substance P, which have been reported in many inflammatory skin conditions, including alopecia areata, atopic dermatitis, and psoriasis [24].

The main differential diagnosis of hair diseases includes folliculitis decalvans (FD), followed by lichen pla- 
Table 1. Classification of keratosis pilaris atrophicans subtypes and their distinguishing features

\begin{tabular}{ll}
\hline Subtype & Clinical features \\
\hline $\begin{array}{l}\text { Keratosis follicularis } \\
\text { spinulosa decalvans }\end{array}$ & $\begin{array}{l}\text { Diffuse cutaneous follicular } \\
\text { hyperkeratosis and scarring alopecia of } \\
\text { the scalp, eyebrows, and eyelashes }\end{array}$ \\
\hline $\begin{array}{l}\text { Keratosis pilaris } \\
\text { atrophicans faciei }\end{array}$ & $\begin{array}{l}\text { Diffuse cutaneous follicular } \\
\text { hyperkeratosis mainly involving the } \\
\text { temples and/or cheeks }\end{array}$ \\
\hline $\begin{array}{l}\text { Ulerythema } \\
\text { ophryogenes }\end{array}$ & $\begin{array}{l}\text { Diffuse cutaneous follicular } \\
\text { hyperkeratosis and scarring alopecia } \\
\text { mainly involving the lateral eyebrows }\end{array}$ \\
\hline $\begin{array}{l}\text { Atrophoderma } \\
\text { vermiculatum }\end{array}$ & $\begin{array}{l}\text { Red papules of the cheeks progressing to } \\
\text { reticulated atrophic cicatricial elements }\end{array}$ \\
\hline
\end{tabular}

nopilaris and lichen spinulosus (LS). FD is characterized by relapsing of follicular pustular lesions. It is also called tufted folliculitis since a common feature is the presence of 10-15 hairs emerging from a single follicular opening. It predominantly affects young and middle-aged male adults. The etiology is not fully understood, even if $S$. aureus seems to play an important role. FD involves the vertex and occipital area of the scalp, often beginning with a patch of hair loss with pustules, crusts, and tufted hairs, which are pathognomonic of the disease. Bleeding, pain, and burning sensation can be referred by the patient [25]. Trichoscopic features change according to the inflammatory activity, and they are tufted hairs, perifollicular erythema, perifollicular hemorrhages, follicular pustules, yellow tubular scaling, and yellow crusts [26].

In most cases, diagnosis is due to trichoscopy, but in doubtful ones, a biopsy of an active lesion can be performed. Lichen planopilaris typically affected middleaged patients and is characterized by 1 or multiple areas of alopecia with irregular shape and margins, frequently localized in the central scalp with intense itching. Often, it is possible to observe inflammatory manifestations together with skin atrophy with naked eye. Physical examination of the oral mucosa, skin, and nail may highlight typical manifestations in other areas. Using trichoscopy, perifollicular erythematous papules and acuminate hyperkeratotic follicular spines are seen together with the absence of follicular ostia. Trichoscopic features may be similar to other cicatricial hair diseases; therefore, histopathology is mandatory [3].

LS, a rare and benign disorder is characterized by follicular keratotic papules involving the neck, buttocks, ab-

Usefulness of Trichoscopy in a Rare Scalp Disease domen, trochanteric regions, knees, and extensor surfaces of the arms. Above all, LS has a predilection for acral areas unlike keratosis pilaris, which is frequently limited to the upper aspects of the arms and legs [13].

Differential diagnosis of KSFD also includes IFAP syndrome (i.e., ichtyosis-follicularis-alopecia-photophobia), characterized by cutaneous follicular hyperkeratosis, nonscarring alopecia, severe photophobia, corneal dystrophy, and often mental retardation [14, 23, 27]. The congenital and non-cicatricial nature of alopecia, absence of cutaneous inflammation and "nutmeg grater" appearance of the skin differentiates IFAP syndrome from KFSD [28]. Other differential diagnoses include keratitis ichthyosis deafness syndrome, atrichia with popular lesions, and hereditary mucoepithelial dystrophy $[27,29]$. To the best of our knowledge, the trichoscopic evaluation of KFSD has never been described before in the literature. The role of trichoscopy is not diagnostic for KFSD, but it is useful to differentiate, at the beginning, cicatricial alopecia versus non-cicatricial alopecia. In our case, trichoscopy suggested us the diagnosis, especially with the findings of tufted hair and loss of follicular ostia, together with yellow dots and dystrophic hair at eyebrows and eyelashes.

We decided to perform biopsy to differentiate the disease primarily from $\mathrm{FD}$, and also from other scarring alopecias. Trichoscopy is crucial for selecting the best place for scalp biopsy, as in other hair disorders [30]. In addition, it helps to follow the patient over time and evaluate the therapeutic response.

From a histopathological viewpoint, in advanced disease or end stages, KFSD is classified by the NAHRS as a lymphocytic alopecia [31]. However, the initial lesions also show a neutrophilic infiltrate [9]. The initial defect seems to be abnormal keratinization that gives rise to hypergranulosis and compact hyperkeratosis in the upper part of the infundibulum [9], which correlate clinically with follicular plugs. In the next phase of acute inflammation, spongiosis appears along with a neutrophilic infiltrate in the infundibulum and adjacent epidermis. The course includes the appearance of a lymphocytic infiltrate associated with perifollicular fibrosis, predominantly in the upper part of the follicle. In the end stages, fibrosis is observed with the presence of foreign-body granulomas surrounding the hair shafts, as well as destruction of the hair follicle [32, 33].

There is no specific treatment for KSFD. Topical keratolytic agents and emollients improve skin texture, and combination with topical and/or intralesional corticosteroids can be used for symptomatic relief. A transient im- 
provement has been showed after such a treatment $[9$, 34]. Oral antibiotics such as tetracyclines, sulfonamides, macrolides, penicillins, and rifampin may be administered during pustular flares of disease [34].

Etretinate and isotretinoin might be useful but were reported to produce variable results $[23,35]$. Oral retinoids are effective in the early phase of disease when active perifollicular infiltrate is present and should be continued for 6-12 months for an optimum response [16]. Retinoids improve disorders of keratinization, act by downregulating epidermal proliferation, and reduce the process of follicular hyperkeratosis and inflammation [32]. Long-pulse non-Q-switched ruby laser could be useful in recalcitrant KSFD [33].

\section{Conclusion}

KFSD is a rare $\mathrm{X}$-chromosomal disorder. It consists of follicular hyperkeratosis of the skin, scarring alopecia of the scalp, absence of the eyebrow, and corneal degeneration. Both clinical and genetic heterogeneity have been described, while trichoscopy has never been evaluated as far as our review. The gold standard for diagnosis remains histopathology, but trichoscopy can be very useful to select the site of scalp biopsy and for the follow-up of the patient.

\section{Acknowledgement}

Authors acknowledge Dr. Cosimo Misciali (Dermatology, Department of Experimental, Diagnostic and Specialty Medicine (DIMES), University of Bologna, Italy) for the pathology study and pathology pictures and captions.

\section{Statement of Ethics}

The manuscript was conducted ethically in accordance with the World Medical Association Declaration of Helsinki. The patient has given written informed consent to publish photos and details of the case.

\section{Conflict of Interest Statement}

There are no conflicts of interest.

\section{Funding Sources}

The authors did not receive any funding.

\section{Author Contributions}

A.A., G.B., M.S., and A.D.A. contributed equally to the manuscript for the conception and writing of the manuscript and the review of the literature. B.M.P. contributed especially for the critical revising and final approval of the manuscript.

\section{References}

1 Azakli HN, Agirgol S, Takmaz S, Dervis E. Keratosis follicularis spinulosa decalvans associated with leukonychia. West Indian Med J. 2014 Sep;63(5):552-3.

2 Oosterwijk JC, Nelen M, van Zandvoort PM, van Osch LD, Oranje AP, Wittebol-Post D, et al. Linkage analysis of keratosis follicularis spinulosa decalvans, and regional assignment to human chromosome Xp21.2-p22.2. Am J Hum Genet. 1992 Apr;50(4):801-7.

3 Somani N, Bergfeld WF. Cicatricial alopecia: classification and histopathology. Dermatol Ther. 2008 Jul-Aug;21(4):221-37.

4 Chauhan RK, Sankhwar S, Tripathi R, Pandey SS. A rare presentation of keratosis follicularis spinulosa decalvans in female twins. Indian J Dermatol Venereol Leprol. 2018 Sep-Oct; 84(5):645

5 Olsen EA, Bergeld WF, Cotsarelis G, Price VH, Shapiro J, Sinclair R, et al. Summary of the North American Hair Research Society (NAHRS)-sponsored Workshop on Cicatricial Alopecia, Duke University Medical Centre, February 10 and 11, 2001. J Am Acad Dermatol. 2003;48:103-10.
6 Kunte C, Loeser C, Wolff H. Folliculitis spinulosa decalvans: successful therapy with dapsone. J Am Acad Dermatol. 1998;39(5 Pt 2):891-3.

7 Siemens HW. Keratosis follicularis spinulosa decalvans. Arch Dermatol Syphilol. 1926; 151(1):384-6

8 Porteous ME, Strain L, Logie LJ, Herd RM, Benton EC. Keratosis follicularis spinulosa decalvans: confirmation of linkage to Xp22.13-p22.2. J Med Gen. 1998;35:336-7.

9 Baden HP, Byers HR. Clinical findings, cutaneous pathology, and response to therapy in 21 patients with keratosis pilaris atrophicans. Arch Dermatol. 1994;130(4):469-75.

10 Oosterwijk JC, Richard G, van der Wielen MJ, van de Vosse E, Harth W, Sandkuijl LA, et al. Molecular genetic analysis of two families with keratosis follicularis spinulosa decalvans: refinement of gene localization and evidence for genetic heterogeneity. Hum Genet. 1997;100(5-6):520-4.
11 Rothe MJ, Lucky AW. Are ichthyosis follicularis and hereditary mucoepithelial dystrophy related diseases. Pediatr Dermatol. 1995; 12(2): 195.

12 Van Osch LD, Oranje AP, Keukens FM, van Voorst Vader PC, Veldman E. Keratosis follicularis spinulosa decalvans: a family study of seven male cases and six female carriers. J Med Genet. 1992;29(1):36-40.

13 Boyd AS. Lichen spinulosus: case report and overview. Cutis. 989;43(6):557-60.

14 Puppin D, Aractingi S, Dubertret L, Blanchet-Bardon C. Keratosis follicularis spinulosa decalvans: report of a case with ultrastructural study and unsuccessful trial of retinoids. Dermatology. 1992;184(2):1336.

15 Aten E, Brasz LC, Bornholdt D, Hooijkaas IB, Porteous ME, Sybert VP, et al. Keratosis follicularis spinulosa decalvans is caused by mutations in MBTPS2. Hum Mutat. 2010;31(10): $1125-33$. 
16 Gupta D, Kumari R, Bahunutula RK, Thappa DM, Toi PC, Parida PK. Keratosis follicularis spinulosa decalvans showing excellent response to isotretinoin. Indian J Dermatol Venereol Leprol. 2015;81(6):646-8.

17 Rand R, Baden HP. Keratosis follicularis spinulosa decalvans. Report of two cases and literature review. Arch Dermatol. 1983;119(1): 22-6.

18 Britton H, Lustig J, Thompson BJ, Meyer S, Esterly NB. Keratosis follicularis spinulosa decalvans: an infant with failure to thrive, deafness and recurrent infections. Arch Dermatol. 1978;114:761-4.

19 Janjua SA, Iftikhar N, Pastar Z, Hosler GA Keratosis follicularis spinulosa decalvans associated with acne keloidalis nuchae and tufted hair folliculitis. Am J Clin Dermatol. 2008; 9(2):137-40.

20 Lacarrubba F, Dall'Oglio F, Rossi A, Schwartz RA, Micali G. Familial keratosis follicularis spinulosa decalvans associated with woolly hair. Int J Dermatol. 2007;46(8):840-3.

21 Azakli HN, Agirgol S, Takmaz S, Dervis E. Keratosis follicularis spinulosa decalvans associated with leukonychia. West Indian Med J. 2014;63(5):552-3.

22 Callaway SR, Lesher JL. Keratoses pilaris atrophicans: case series and review. Pediatr Dermatol. 2004;21:14-7.
23 Alfadley A, Al Hawsawi K, Hainau B, Al Aboud K. Two brothers with keratosis follicularis spinulosa decalvans. J Am Acad Dermatol. 2002;47(5 Suppl):S275-8.

24 Doche I, Hordinsky M, Wilcox GL, Valente NS, Romiti R. Substance P in keratosis follicularis spinulosa decalvans. JAAD Case Rep. 2015;1(6):327-8.

25 Otberg N, Kang H, Alzolibani AA, Shapiro J. Folliculitis decalvans. Dermatol Ther. 2008 Jul-Aug;21(4):238-44.

26 Saceda-Corralo D, Moreno-Arrones OM, Rodrigues-Barata R, Rubio-Lombraña M, MirBonafé JF, Morales-Raya C, et al. Trichoscopy activity scale for folliculitis decalvans. J Eur Acad Dermatol Venereol. 2020 Feb;34(2): e55-7.

27 Eramo LR, Esterly NB, Zieserl EJ, Stock EL, Herrmann J. Ichthyosis follicularis with alopecia and photophobia. Arch Dermatol. 1985; 121(9):1167-74.

28 Koenig A, Happle R. Linear lesions reflecting lyonization in women heterozygous for IFAP syndrome (ichthyosis follicularis with atrichia and photophobia). Am J Med Genet. 1999; 85:365-8.
29 Rothe MJ, Lucky AW. Are ichthyosis follicularis and hereditary mucoepithelial dystrophy related diseases. Pediatr Dermatol. 1995; 12(2):195.

30 Tosti A, Whiting D, Iorizzo M, Pazzaglia M, Misciali C, Vincenzi C, et al. The role of scalp dermoscopy in the diagnosis of alopecia areata incognita. J Am Acad Dermatol. 2008 Jul; 59(1):64-7.

31 Maroon M, Tyler WB, Marks VJ. Keratosis pilaris and scarring alopecia. Keratosis follicularis spinulosa decalvans. Arch Dermatol. 1992;128(3):397-400.

32 Sellheyer K, Bergfeld WF. Histopathologic evaluation of alopecias. Am J Dermatopathol. 2006;28(3):236-59.

33 Bernárdez C, Molina-Ruiz AM, Requena L. Histologic features of alopecias: part II: scarring alopecias. Actas Dermosifiliogr. 2015; 106(4):260-70.

34 Bellet JS, Kaplan AL, Selim MA, Olsen EA. Keratosis follicularis spinulosa decalvans in a family. J Am Acad Dermatol. 2008;58(3):499502

35 Hallai N, Thompson I, Williams P, Anstey AV. Folliculitis spinulosa decalvans: failure to respond to oral isotretinoin. J Eur Acad Dermatol Venereol. 2006;20(2):223-4. 